\title{
Public Policy for Corporate Social Responsibility and Governance for Sustainable Tourism Development in Greece
}

\author{
Evangelos Taliouris
}

Adjunct Lecturer, Department of Business Administration, Technological Educational Institute of Crete, Greece

Nikolaos Trihas

Adjunct Lecturer, Department of Business Administration, Technological Educational Institute of Crete, Greece

\begin{abstract}
Business innovation, employment generation, environmental sustainability and good governance were some of the fundamental issues that crisis highlighted in Greece as prerequisites for sustainable development. The tourism sector sustainability in parallel with environmental modernization competiveness and social welfare is a complicated and a non linear policy task. The sustainable development in European Union and member states such as Greece is crucial for 2020 and 2030. Moreover, it is essential for the tourism sector's differentiation-competiveness but local societies' welfare too, because it holds a significant share of GDP in Greece. This paper combines literature review, theoretical investigation and political discourse analysis in European Union for CSR and SD. The main goal is to provide a comparative policy analysis framework, which will link European policy framework for SD and CSR with tourism sector in Greece. From a public policy perspective and governance, tourism is an interdisciplinary and multitasking policy field (e.g. agro-food and culture), because influences different policy tasks as well as different stakeholders. The business sector in tourism is an essential stakeholder for sustainable development, whilst its corporate social responsibility is an important factor. The existing policy framework for corporate social responsibility and responsible entrepreneurship in European Union and Greece indicates potentials for tourism sector, in parallel with the international quality standards and criteria. The Sustainable Development Agenda for 2030 is a policy framework that influences CSR policy implementation and sets critical development issues and indicators for development activities with great socioeconomic impact and environmental footprint such as tourism.
\end{abstract}

Keywords: corporate social responsibility, sustainable development, public policy, tourism, Greece.

JEL Classification: L26, L38, L83, M14, Z32.

(C) The Authors, 2017. This article is published with open access at ARMG Publishing.

\section{Introduction}

The European business community was always a crucial stakeholder towards sustainable development, social welfare and environmental protection. Since 2001, Corporate Social Responsibility (CSR) is a policy topic in European Union (EU), therefore business sector contribution to sustainable development (SD) is getting more viable (Commission of the European Communities, 2001; 2002a; 2002b); especially in particular sectors with great environmental and socioeconomic impacts such as industry, transportation and tourism. The policy discourse for CSR in policy making formulation in EU has been based on CSR business case as well as its political dimensions through topics such as public procurement, responsible supply chains, anti corruption policies, employment generation, reporting and disclosure (EC, 2007; 2009; 2011; 2014c). Hence, the issue of corporate citizenship and the business sector potentials towards that indicates good governance and social responsibility as prerequisites for SD not only for private sector but for public too.

Business community since $19^{\text {th }}$ century in Europe investigates through practices its social responsibility features and characteristics via social initiatives (e.g. salary, workers benefits) (Banerjee, 2008; Carroll, 2008; Garriga and Mele, 2004). In $20^{\text {th }}$ century many of these initiatives turn into regulation (e.g. labor law, environmental standards) and the space for CSR became thinner as well as the gap from responsible entrepreneurship in theory and practice (Taliouris, 2014). In $21^{\text {st }}$ century the European approach for CSR defined twice in 2001 and 2011, whilst policy formulation is taking place explicitly up till now in different policy realms (Commission of the European Communities, 2001; 2011). Consequently, EU business sector is a significant contributor to SD, whilst the overall policy framework for CSR is significant to be taken into consideration in tourism sector entrepreneurship, especially in member states where tourism is a very dynamic 
development activity. The tourism sector (e.g. hotels, transportation, tour operators) underlines significant issues for CSR in term of employment, environmental protection, climate change and economic responsibilities (e.g. profitability). The Europe 2020 Strategy as well as the common policy for tourism are significant steps towards SD and deal successfully with crisis negative socioeconomic and environmental challenges (Commission of the European Communities, 2010a; 2010b). One such country is Greece where tourism is vital to the economy since it holds a significant share of GDP, while is associated with other sectors such as agro-food and culture (Ministry of Tourism, 2013).

The sustainability issues are vital and crucial in such development framework because tourism is an activity that contributes significantly in local societies' economic growth, while at the same time its social and environmental impacts are significant. The policy making for CSR and its linkages with SD is a mainstream policy topic in EU (Commission of the European Communities, 2010b) including tourism, while the incorporation of Unite Nations SD Strategy 2030 in European economy and businesses' operations is an objective (Commission of the European Communities, 2016). The SD political objectives for tourism are based on the approach 'think global act local' through the incorporation of World Tourism Organization standards (2015), which is essential in order to analyze and understand better the EU policy framework, its linkages with CSR and its implementation in Greece. Therefore, this paper will be based on a qualitative research framework, which will combine literature review, as well as theoretical investigation and political discourse analysis for CSR and SD in EU and Greece at tourism sector. The main goal is to provide a multilevel comparative policy analysis framework, which will link European policy framework for SD and CSR with tourism sector in Greece. This analysis will try to indicate the potentials for Greece towards the tourism policy objectives and SD Strategy 2030 via evidence based policy analysis.

\section{European Policy for Tourism and Sustainable Development Agenda 2030}

Discussion about development process as well as its pillars is perpetual and lasts since industrial revolution. The different perspectives about development and economic growth were not very clear in terms of terminology as they are nowadays. The notion of development incorporates economic growth in combination with human development issues (e.g. education, equality) and quality of life (Thomas, 2004). These variables indicate social welfare as an important pillar in development process as the economic one. This discussion was further enriched especially in post war period and in particular during 60s, when an overall social and environmental awareness took place in Europe via the development and strength of grassroots movements. These green movements and political discussions as well, affected the overall discussion about development, entrepreneurship, global governance and policy. Hence, the environmental pillar has been introduced in the development process in order to better understand issues such as environmental pollution and degradation, climate change and natural capital significance (UNEP, 2002; WCED, 1987). Therefore the orthodox view about development (e.g. economic growth, employment, living conditions) (Thomas, 2004) was accompanied with other development variables from social and environmental pillar.

During 60s and 70s the skepticism about development process has underlined the environmental issues as significant, especially through the indication of limits to growth and the need for environmental sustainability (Hardin, 1967). The future generations' capability in development became an ethical and a political right, which influenced the political discourse about environmental sustainability and social welfare. These discourses concluded in United Nations Stockholm Declaration in 1972; a significant political step for environmental protection and SD. During 80s, the debate about development as method and notion had conceptualized in UN Brundtlant Report "Our Common Future" in 1987. The SD is the major outcome from this process and its definition: "The development that meets the needs of the present without compromising the future generations' capability to meet their own needs" (WCED, 1987).

The definition above is the ultimate base on which the future political steps in SD were based on (e.g. Rio 1992, Johannesburg 2002, Rio 2012) as well as the Millennium Development Goals and the SD Agenda 2030 (Commission of the European Communities, 2016; UNWTO, 2015; UN, 2015). The latter is a UN road map that incorporates 17 goals: 1 . No poverty; 2. No hunger; 3. Good health and well being; 4. Quality education; 5. Gender equality; 6. Clean water and sanitation; 7. Affordable and clean energy; 8. Decent work and economic growth; 9. Industry, innovation and infrastructure; 10. Reduced inequalities; 11. Sustainable cities and communities; 12. Sustainable production and consumption; 13. Climate change; 14. Life bellow water; 15. Life on land; 16. Peace - justice and good institutions; 17. Partnership for the goals. These goals interrelated with various political topics and influence regional (EU) and national SD policy among sectors, including tourism (UNWTO, 2015). 
The World Tourism Organization (2015) indicates tourism sustainable transition of tourism sector as vital for SDGs fulfillment via the linkages with each goal separately in the book "Tourism and Sustainable Development Goals". The UNWTO in 2017 introduced the International Year for Sustainable Tourism for Development. UNWTO declared "the importance of international tourism, and particularly of the designation of an international year of sustainable tourism for development, in fostering better understanding among peoples everywhere, in leading to a greater awareness of the rich heritage of various civilizations and in bringing about a better appreciation of the inherent values of different cultures, thereby contributing to the strengthening of peace in the world" (UN, 2017: 3). In particular, tourism sector and services incorporated in Agenda 2030 and SD goals, due to their significant environmental and social impact. Therefore, UNWTO (2017a) indicated three goals in which tourism is directly incorporated: The SDG 8 because tourism significantly contributes in employment generation; The SDG 12 because tourism can contribute in sustainable consumption and production, as the businesses in these sectors (e.g. hotels, tour operators) influence other services and trade in international supply chain; The SDG 14 because tourism environmental footprint in natural capital and water (oceans-coastlines) is significant and their conservation is a policy priority (e.g. Greece has the $6^{\text {th }}$ larger coastline in the world). Moreover, UN and WTO highlight also the "important role of sustainable tourism as a positive instrument towards the eradication of poverty, the protection of the environment, the improvement of quality of life and the economic empowerment of women and youth and its contribution to the three dimensions of sustainable development, especially in developing countries" (UN, 2016: 3).

The EU is a dynamic player in SD policy and international standards as well as tourism and the SD Agenda 2030 (Commission of the European Communities, 2016). In 2016, EU introduced a policy framework towards the SDGs 2030 and adjusted them in European socioeconomic and environmental risks. The approach 'think global act local' in SD Agenda is essential from many reasons, starting from the fact that EU and its member states (e.g. France, Germany, Italy, Spain, Netherlands) are dynamic political players both regionally and internationally in SD issues and CSR (EC, 2011; 2014c). Moreover, the EU business sector operates in many different places and implements foreign direct investments. Therefore the issue of CSR and SD is crucial not only for public policy making but for their adjustment in domestic and international business practices according to European Parliament (2013a; 2013b). Tourism as a sector and within its business activities in Europe and its member's states has a significant environmental and socioeconomic impact. Additionally, tourism sector compliance with SD and tourism business activities contribution in environmental and social sustainability is significant (e.g. employment generation, economic growth, water management) (EU, 2017).

According to Commission of the European Communities (2010b) tourism is a major economic activity with a broadly positive impact on economic growth and employment in Europe, while its environmental responsibility is high due to the fact that Natura 2000 network covers more than $17 \%$ of European territory and areas of interest for tourism (e.g. Greece). Moreover responsible water management, fauna and flora conservation in rural or mountain areas is a prerequisite for $\mathrm{SD}$ in tourism because the EU is the most popular destination because of this unique combination between culture and environment. The cultural capital and its diversity in EU cities (Paris, Rome, Berlin, Athens, Amsterdam, Brussels, Madrid etc.) are a pole of attraction among international tourists ( 300 of the 800 UNESCO World Heritage sites are within the EU). These features set EU as the top destination worldwide (40.5\% of arrivals around the world). For instance, in 2016 the international tourist arrivals in EU reached 500.1 million (UNWTO, 2017b). Furthermore, the cultural heritage in combination with rural environment and nature indicates tourism as development accelerator and at the same time as a potential contributor for $\mathrm{SD}$, because hotels and tourism infrastructures requires an environmental plan and management not only for urban environment but also for rural areas and coastlines.

Moreover, European tourists contribute to growth and socioeconomic development because they travel often (Commission of the European Communities, 2010b) and most of the times are characterized as repeaters. Hence, this feature is in practice a significant support for member states in particular the Mediterranean (e.g. Greece, Spain, Portugal, Italy), while the tourism policy external dimension (tourist flows from third countries) is vital for economy and employment. What is also remarkable at this point is the reference in Lisbon Treaty about tourism significance, which is mentioned in Article 195. In Commission of the European Communities (2010b: 6) communication about the EU political framework for tourism it is also pictured: "Europe must offer sustainable and high-quality tourism, playing on its comparative advantages, in particular the diversity of its countryside and extraordinary cultural wealth". To sum up, another element that is also incorporated in this political framework for tourism is the linkage with Information and Communication Technologies (ICTs) via the Digital Agenda for Europe (EC, 2014a) and their contribution in services quality and differentiation of 
tourism destination and forms (e.g. accessible tourism), due to the increase familiarity and use of ICTs tools and devices by tourists for information or booking services.

Another important tool is the European Toolkit Indicator System (2015), which is a toolkit for sustainable destination management in EU. According to Commission of the European Communities (2015) is a multitasking tool: management (supporting destinations who want to take a sustainable approach to destination management), monitoring system (easy to use for collecting data and detailed information and to let destinations monitor their performance from one year to another) and information tool (not a certification scheme but useful for policy makers, tourism enterprises and stakeholders). The development of informational tools and materials to guide entrepreneurs and policy makers in tourism sector investments and fund raising is essential, for instance "Guide on EU funding for the tourism sector" by European Commission (2014b). This Guide provides information about the EU funding opportunities from institutions or programmes 2014-2020, such as European Regional Development Fund, European Social Fund, Cohesion Fund, Maritime and Fisheries Fund, Agriculture Fund for Rural Development, Erasmus +, Life, Horizon, COSME, Creative Europe, Employment and Social Innovation. Therefore, this type of financial instruments indicates tourism for EU as strategic and SD as a permanent feature and prerequisite for its evolution in Europe and its member states such as Greece.

\section{Tourism development in Greece}

Tourism is vital to the Greek economy, since it accounts for 18.6 per cent of GDP and is a significant source of foreign exchange (12.7 billion euro international tourism receipts), generated by the 24.7 million tourists who visited the country during 2016. Around 23.4 per cent of the workforce is employed in the tourism industry according to official figures (SETE, 2017a). Undoubtedly, Greece is among the top tourist destinations worldwide, with a well-established tourism sector and unique tourist attractions. At the same time, however, the country is also suffering from a range of factors relating to tourism which may act to prevent the Greek tourism sector fulfilling its true potential and thus contributing more fully to national welfare (Boniface and Cooper, 2005).

Tourism development in Greece is for its greatest part based on islands where the $3 \mathrm{~S}$ (sea, sun, sand) model has been applied for many years. Conventional (mass) tourism in the islands is largely based on organized charter flights for foreign tourists (Spilanis and Vayanni, 2004). Starting with the economic success of the islands, where this model was developed in the 1960s and 1970s (in Rhodes, Corfu, Mykonos etc.), mass tourism has sprung up in most regions of the country (Tsartas, 2004). The majority of tourists visit Greece for recreational reasons - in search of sun, sand and sea. However, this type of tourism development caused several negative economic, environmental and social impacts in many regions of the country that have adopted the mass tourism model. The main problems concern the intense seasonality of demand for this type of tourism (56\% of international tourist arrivals are recorded in July, August and September), the progressive reduction of the economic benefits (related to the life cycles of the products in many regions, which were progressively being downgraded), the domination by foreign tour operators (who pay low prices for products and services), the spatial concentration of tourism facilities and infrastructure ( $70 \%$ of hotel beds are concentrated in 4 areas of the country), the frequent disregard for land-use planning and urban planning provisions in most regions with a developed and organized infrastructure, the intense competition among existing or emerging mass tourism destinations, and the downgrading of the natural and built environment caused by the fast and uncontrolled increase in tourist flows (Boniface and Cooper, 2005; SETE, 2017a; Tsartas, 2004). In some cases, the phenomenon is so intense - and thus difficult to reverse - that, in combination with the low quality of services, it contributes to the continuous degradation of the tourist product and the reduction of profits for host communities and for the national economy (Spilanis and Vayanni, 2004).

\section{The tourism sector and the policy in Greece: the issues of sustainable development and corporate social responsibility}

Greece is a member state that is based upon tourism sector, including the services that derived from this development and business activity (e.g. transportation, trade). In 2013 a National Strategy 2014-2020 for tourism sector and relevant activities (e.g. environmental criteria and guidelines) has been developed (Ministry of Tourism, 2013). The facts above indicates Greece as a member state that Europeanization and political cohesion in tourism is developing, but also because tourism is mainly identified in such Regions as: Crete, South Aegean (e.g. Dodecanese, Cyclades), Central Macedonia (e.g. Thessaloniki, Chalkidiki), Ionian Islands (e.g. Corfu, North Aegean islands) and Attica (Athens, Piraeus). Moreover, the local overconcentration of 
tourism activities is a weakness in terms of SD. These places are cities in combination with rural characteristics, while insularity in some of them is the main feature. Hence, their SD potentials and the implementation of existing environmental plan for tourism (Ministry of Environment, 2013) is a prerequisite for Greece, in order to meet SDGs by 2030 and to achieve a prosperous future in terms of environmental sustainability, human development and economic growth.

The Ministry of Tourism (2013) via this strategic framework introduced a policy plan for tourism development in the programming period 2014-2020, whilst identified and analyzed the situation in parallel with the European policy framework and funding opportunities through structural funds (e.g. European Regional Development Funds, European Social Fund). For instance, some of the main challenges that tourism sector in Greece must deal with are insularity and the public infrastructures for tourism and transportation. This type of interventions will improve the local population well being but at the same time will provide significant potentials for tourism sector (e.g. home ports, yachting) and business activities (e.g. hotels) increase (Ministry of Tourism, 2013; Ministry of Environment, 2013). This linkage with the social pillar of SD context indicates that tourism is an activity indeed, which can be described as an integrated assessment among development sectors and stakeholders (e.g. primary, constructions), including local state.

Furthermore, this strategy underlined another challenge that local authorities in combination with business sector must deal with; this is climate change. Due to the fact that insularity in combination with the temperature increase might influence negatively tourism sector services, the strategic framework underlines as crucial environmental modernization and energy efficiency not only for businesses and especially hotels. This approach seems to be an alternative solution towards the competitiveness increase by others destinations in North EU, mainly because of temperature increase (Ministry of Tourism, 2013). The policy framework towards this seems to focus on policies for green infrastructures and sustainable forms of tourism services and destinations (e.g. Blue Growth Strategy) (Commission of the European Communities, 2017). What is also remarkable towards that direction is that this policy sets a will, to enrich tourism sector activities via clusters and synergies with primary sector and cultural capital (e.g. renovations, ports).

Furthermore, this policy framework by Ministry of Tourism (2013) indicates a development context that is consisted of eleven (11) thematic objectives. Some of them are linked directly with SD and the business responsibility such as energy efficiency and emissions management (objective 4), climate change adaptability (objective 5), sustainable transportation and environmental conservation (objectives $6 \& 7$ ). The natural capital in Greece is the ultimate base on which tourism industry must be based on in terms of energy, sightseeing, resources and water management. Hence its conservation is vital in order to be linked with sustainable tourism development (e.g. agritourism, ecotourism, wine tourism). Moreover, some other goals are based on the social pillar of development such as the tourism industry influence in employment generation, social inclusion and education.

What is important at this point is that national tourism strategy and future orientation towards SD is also pictured at Regional Level. For instance the Region of Crete development plan 2014-2020 (Region of Crete, 2014) sets specific targets and 11 objectives. The tourism is referred in most of the policy targets and investment priorities such as environmental innovation and clusters development, competiveness via ICT infrastructures or human development and employment generation. At this point it is worth to be noted that the Region of Crete has also developed the Smart Specialization Strategy named RIS Crete (Region of Crete, 2015), in which tourism in combination with culture are a policy target with dynamic and innovative characteristics. According to the vision of the Region of Crete this development plan $2014-2020$ is based on the phrase "Dynamic and Sustainable Crete" (Region of Crete, 2015: 6). The term dynamic is mainly analyzed as a policy antidote to crisis via public and private investments in sectors (including tourism). The term sustainable in terms of economy is to achieve SD based on regional characteristics (e.g. rural sector, tourism), in terms of environment is to sustain natural and cultural resources, and in terms of society is to set the framework for an inclusive development, social welfare and quality of life. The latter is directly linked with crisis negative socioeconomic outcomes, which have set an important number of population (and in particular young population) under the risk of poverty. According to recent data from Eurostat (2017a; 2017b; 2017c; $2017 \mathrm{~d}$ ) the "population at risk of poverty and social exclusion" has reached the $35.6 \%$ in Greece (2009: $34.6 \%)$ and in the area of Aegean islands and Crete this percentage have reached 37.5\% (2009: 31.3\%, 2015: 39.4\%). The living conditions compared to 2009 are getting worse because of the crisis; a fact that is also described further through the indicator "Severe material deprivation rate" in Greece (2006: 22.4, 2009: 19.5) and Aegean islands and Crete (2006: 23,1 2009: 15,6). The employability via the indicator "People living in households with very low work intensity" in Aegean Islands and Crete (12.7\%) are the only indicator that performs better 
than Greece $(17.1 \%)$ in 2016. Nevertheless unemployment rate in $2^{\text {nd }}$ quarter of 2017 is still high in total population in Greece $(21.1 \%)$ and Crete $(15.6 \%)$, while in young population is extremely high (15-19: $55 \%$, 20-24: 42.1\%, 25-29: 30.1\%) (Hellenic Statistical Authority, 2017). The Region of Crete has one of the lowest unemployment rates as well as other Regions (South Aegean or Ionian Islands); a fact that might be influence by tourism employment generation. The Region of Crete employment is mainly based on primary sector and tourism services; the latter holds the $31 \%$ of regional employment in 2013 and ranked Crete at the level of 5 in the European Index of sectors expertise (Region of Crete, 2014; 2015). The latter under circumstances can generate significant potentials for tourism if only linked with the indicator of educational attainment level at tertiary education (30-34) in 2016. This Eurostat indicator underlines a significant strength of Greece (42.7\%) and the Region of Crete (40.7\%) compare to EU27 (39.2\%) and Euro Area 19 (37.6\%), which is human capital high level skills, education and capabilities.

Despite the negative outcomes from the crisis and the development asymmetries, the tourism sector dynamic characteristics in combination with the business activities and high investments rate is still an alternative. This fact underlines tourism in parallel with primary sector as significant contributors to employment and economic growth. More specifically, at the $16^{\text {th }}$ Conference of the Association of Greek Tourism Enterprises in October 2017, significant conclusions has taken place, such as that 300 investments proposals for 4 and 5 stars hotels since 2016 as well as the estimations of tourists' arrivals for 2018 (approximately 30 million) or the development rural tourism label (SETE, 2017b). The latter introduced an explicit discussion about SD and the business contribution towards it in that conference, and according the official conclusions documents (SETE, 2017b) many stakeholders from civil society and business community underlined the SD significance as well as the responsible entrepreneurship initiatives in tourism. Therefore, the SDG 8-12-14 for 2030 might be met at national and regional level because employment, environmental sustainability and sustainable entrepreneurship are the prerequisites for a competitive tourism industry. Although EU structural funds, national and regional budgeting is significant towards these investment priorities, the private sector must contribute via responsible and sustainable entrepreneurship.

The CSR in tourism and the regional business activities is developing and taking place by silent CSR characteristics. The development of environmental management mechanisms and services are developing, while at regional policy level important steps have been undertaken. As it was mentioned above, the RIS strategy in Crete and the regional development plan have indicated many financial instruments that foster environmental sustainability, competiveness and employment generation in businesses at tourism sector.

\section{Conclusions}

In conclusion, it must be also noted that during policy process it must be taken into consideration that policy making for CSR in general and in particular for tourism sector must be in parallel with EU policy objectives but also international market trends and initiatives for CSR (SETE, 2017b; EC, 2014c). Therefore, a blueprint approach for CSR in tourism is not always applicable, not only because of the different public policy models for CSR but also because the approach 'one size fits all' does not refer to the whole needs and features of tourism business sector. Moreover, the European approach and policy applications for CSR must be carefully analyzed via the National Public Policy reports of EU Commission $(2007,2011,2014)$ in order to investigate the best practices and to use also the appropriate policy tools (legal, economic, partnering, informational, hybrid), which will fit both to local business needs as well as institutional setting and regional policy objectives.

Moreover, the improvement of business sector familiarity with CSR in tourism sector is an interregional and national goal. This is essential because according to the new Directive 2014/95/EU, many corporations will must disclose in their management reports, information on policies, risks and outcomes regarding environmental, social and employee aspects, respect for human rights, anticorruption and bribery issues, and diversity in their board of directors. This is very important for business sector at tourism because it might influence its environmental impact, its branding as well as its social position at local labor market and society (Road CSR, 2017). In parallel to that Directive and legislation for non-financial reporting, the EY Greece (2015) report for sustainability reporting in Greece highlights the fact that this business action towards transparency, SD and CSR is developing. According to ICAP (2017), CSR is getting popular in Hellenic business sector in particular in Human Resource (37\%), in Society (31\%), in Environment (19\%) and Market (13\%). These facts indicates the transformation of implicit CSR to explicit CSR (IMPACT, 2013; Matten and Moon, 2008) not only in public policy making but also business sector activities in Greece (including tourism) both at regional and national level. Hence, the silent CSR approaches that have been indicated in Greece both at private and public sector activities (Taliouris, 2014), are getting gradually more explicit and relevant to EU 
policy objectives and directions (e.g. the national strategy for CSR in 2014 and 2017) (Ministry of Economy and Development, 2014; 2017) Despite, the potentials and the development of CSR initiatives both directly (e.g. non financial reporting) and indirectly (e.g. Green Tourism financial aid programme) (EC, 2011), many steps need to be undertaken in Greece, in order SD and responsible entrepreneurship to improve tourism sector activities and to share equally and responsible the added value to local economy, society and stakeholders.

\section{References}

1. Banerjee, B.S. (2008). Corporate Social Responsibility: The Good, the Bad and the Ugly. Critical Sociology, 34(1), 51-79.

2. Boniface, B.G., \& Cooper, C. (2005). Worldwide Destinations: The Geography of Travel and Tourism. Oxford: Elsevier Butterworth-Heinemann.

3. Carroll, A. (2008). A history of Corporate Social Responsibility: Concepts and Practices. pp. 19-46 in A. Crane, A. McWilliams, D. Matten, J. Moon and D. Siegel (Eds.), Oxford Handbook of Corporate Social Responsibility. Oxford: Oxford University Press.

4. Commission of the European Communities (2001). Green paper. Promoting a European framework for Corporate Social Responsibility. Brussels: CEC.

5. Commission of the European Communities (2002a). Corporate Social Responsibility: A business contribution to Sustainable Development. Brussels: CEC.

6. Commission of the European Communities (2002b). Towards a global partnership for sustainable development. Brussels: CEC.

7. Commission of the European Communities (2010a). Europe 2020. A strategy for smart, sustainable and inclusive growth. Brussels: CEC.

8. Commission of the European Communities (2010b). Europe, the world's No 1 tourist destination - a new political framework for tourism in Europe. Brussels: CEC.

9. Commission of the European Communities (2011). A renewed EU strategy 2011-14 for Corporate Social Responsibility. Brussels: CEC.

10. Commission of the European Communities (2016). Next steps for a sustainable European future European action for sustainability. Brussels: CEC.

11. Commission of the European Communities (2017). Report on the Blue Growth Strategy Towards more sustainable growth and jobs in the blue economy. Brussels: CEC.

12. EY Greece (2015). Sustainability reporting practices in Greece: A desk research of published sustainability reports, Volume 2, April 2015.

13. European Commission (2007). Corporate Social Responsibility National Public Policies in the European Union. Directorate-General for Employment, Social Affairs and Equal Opportunities. Luxemburg: EC.

14. European Commission (2009). Towards greater corporate responsibility Conclusions of EU-funded research. Directorate-General for Research Communication Unit. Luxemburg: EC.

15. European Commission (2011). Corporate Social Responsibility National Public Policies in the European Union. Directorate-General for Employment, Social Affairs and Equal Opportunities. Luxemburg: EC.

16. European Commission (2014a). Digital Agenda for Europe. The digital agenda for Europe will help Europe's citizens and businesses to get the most out of digital technologies. Directorate-General for Communication Citizens information. Luxemburg: EC.

17. European Commission (2014b). Guide on EU funding for the tourism sector. Directorate-General for Internal Market, Industry, Entrepreneurship and SMEs. Luxemburg: EC.

18. European Commission (2014c). Corporate Social Responsibility National Public Policies in the European Union. Directorate-General for Employment, Social Affairs and Equal Opportunities. Luxemburg: EC.

19. European Commission (2016). The European Tourism Indicator System ETIS toolkit for sustainable destination management. Directorate-General for Internal Market, Industry, Entrepreneurship and SMEs. Luxemburg: EC.

20. European Union (2017). The new European consensus on development. Our world, our dignity, our future. Brussels: EU.

21. European Union Parliament (2013a). “Report on Corporate Social Responsibility: promoting society's interests and a route to sustainable and inclusive recovery". A7-0023/2013". Brussels.

22. European Union Parliament (2013b). Report on corporate social responsibility: accountable, transparent and responsible business behavior and sustainable growth. 2012/2098(INI)". Brussels.

23. Eurostat (2017a). Educational attainment level at tertiary education (30-34). Available at: http://ec.europa.eu/eurostat/data/database. 
24. Eurostat (2017b). Eurostat Indicator for people at risk of poverty and social exclusion. Available at: http://ec.europa.eu/eurostat/data/database.

25. Eurostat (2017c). People living in households with very low work intensity. Available at: http://ec.europa.eu/eurostat/data/database.

26. Eurostat (2017d). Severe material deprivation rate. Available at: http://ec.europa.eu/eurostat/data/database.

27. Garriga, E., \& Mele, D. (2004). Corporate Social Responsibility Theories: Mapping the Territory. Journal of Business Ethics 53, 51-71.

28. Hardin, G. (1967). The Tragedy of the Commons. Science, 162(3859), 1243-1248.

29. Hellenic Statistical Authority (2017). Manpower Research. Second quarter 2017. Athens.

30. ICAP Group (2017). The ICAP Group's view of the Human Resource Management and Corporate Social Responsibility. Athens: ICAP.

31. Impact (2013) Final Programme and Executive Summary. Headline findings, insights \& recommendations for policy makers, business \& stakeholders. Seventh Framework Programme, European Commission.

32. Matten, D., \& Moon, J. (2008). "Implicit" and "Explicit” CSR: A conceptual Framework for a comparative understanding of corporate social responsibility. Academy of Management Review, 33(2), 404-424.

33. Ministry of Economy and Development (2014). National Strategy for Corporate Social Responsibility. Draft paper. Hellenic Republic. Athens.

34. Ministry of Economy and Development (2017). National Strategy for Corporate Social Responsibility. Hellenic Republic. Athens.

35. Ministry of Enviroment, Energy and Climate Change (2013). Adoption of a modification of a Special Framework for Spatial Planning and Sustainability Development for Tourism and the Strategy of its Environmental Impact Assessment. Hellenic Republic. Athens.

36. Ministry of Tourism (2013). National Development Guidelines in the tourism sector 2014-2020. Hellenic Republic. Athens.

37. Region of Crete (2014). Regional Operational Programme of Crete 2014-2020. Heraklion: Region of Crete.

38. Region of Crete (2015). The Smart Specialization Strategy for the Region of Crete 2014-2020. Heraklion: Region of Crete.

39. Road CSR Interreg Europe (2017) A Roadmap for Integrating Corporate Social Responsibility into EU Member States and Business Practises. The Region of Crete. Available at: https://www.interregeurope.eu/road-csr/.

40. SETE - Association of Greek Tourism Enterprises (2017a). Greek Tourism - Basic Figures 2016. Available at: http://sete.gr/en/strategy-for-tourism/basic-figures-repository/.

41. SETE - Association of Greek Tourism Enterprises (2017b). "Greek Tourism: The perfect balancing act. Exploring the dynamic role of tourism in contributing to environmental, economic and social sustainability. Conslusions". Available at: http://sete.gr/en/conferences-events/conferences/16thconference-2017/.

42. Spilanis, I., \& Vayanni, H. (2004). Sustainable Tourism: Utopia or Necessity? The Role of New Forms of Tourism in the Aegean Islands. In: B. Bramwell (Ed.), Coastal Mass Tourism. Diversification and Sustainable Development in Southern Europe, pp. 269-291. Clevedon: Channel View Publications.

43. Taliouris, E. (2014). Governance, Administration of Organizations and Businesses, and Public Policies for Corporate Social Responsibility. PhD Thesis. Department of Political Science, School of Social Sciences, University of Crete.

44. Thomas, C. (2004). Poverty, development and hunger. In: J. Baylis, \& S. Smith (eds.), The Globalization of World Politics. An introduction to international relations. Oxford University Press.

45. Tsartas, P. (2004). Tourism Development in Greek Insular and Coastal Areas: Sociocultural Changes and Crucial Policy Issues. In: B. Bramwell (Ed.), Coastal Mass Tourism. Diversification and Sustainable Development in Southern Europe, pp. 68-84. Clevedon: Channel View Publications.

46. United Nations Environmental Programme (2002). Chapter 1: Integrating Environment \& Development 2002. Global environmental outlook 3. London: Earth Scan Publications.

47. United Nations (2015). Transforming our world: the 2030 Agenda for Sustainable Development. Resolution adopted by the General Assembly on 25 September 2015. General Assembly.

48. United Nations (2017). International Year of Sustainable Tourism for Development, 2017. Resolution adopted by the General Assembly on 22 December 2015. General Assembly. 
49. United Nations World Tourism Organization (2015). Tourism and the Sustainable Development Goals. Madrid: World Tourism Organization.

50. United Nations World Tourism Organization (2017a). Tourism and the Sustainable Development Goals. Institutional Relations and Resource Mobilization. Available at: http://icr.unwto.org/content/tourism-andsdgs.

51. United Nations World Tourism Organization (2017b). UNWTO Tourism Highlights 2017 Edition. Madrid: World Tourism Organization.

52. World Commission on Environment and Development (1987). Our Common Future. United Nations. 